\title{
The Role of Morphology and Short Vowelization in Reading Morphological Complex Words in Arabic: Evidence for the Domination of the Morpheme/Root-Based theory in Reading Arabic
}

\author{
Salim Abu-Rabia \\ Faculty of Education, University of Haifa Mt. Carmel, Haifa, Israel \\ Email: salimar@edu.haifa.ac.il
}

Received July $1^{\text {st }}, 2012$; revised August $8^{\text {th }}, 2012$; accepted August $18^{\text {th }}, 2012$

\begin{abstract}
This study investigated the reading accuracy of 59 adult highly skilled native Arabic readers in reading morphological complex Arabic words in 6 reading conditions: Isolated words with short vowelization, isolated words without short vowelization, sentences with roots with short vowelization, sentences with roots without short vowelization, sentences without priming roots with short vowelization and sentences without priming roots without short vowelization. The results indicated that roots and short vowelization were good facilitators for these adults highly skilled readers in their reading accuracy of morphological complex Arabic words. The results are discussed in the light of the role of roots as autonomous semantic entities and that the complex morphology of Arabic needs short vowelization for accuracy in reading.
\end{abstract}

Keywords: Arabic Morphology; Morpheme/Root-Based Theory; Morphological Complexity; Reading Accuracy; Roots and Phonology; Short Vowelization

\section{Introduction}

Phonological awareness is related to the acquisition of reading (Bradley \& Bryant, 1983; Stanovich, Cunningham, \& Cramer, 1984; Tunmer \& Nesdale, 1985). Some scholars have claimed a causal link between phonological awareness and reading and that phonological awareness is a crucial precondition for beginning reading (Liberman \& Liberman, 1990; Snowling 1980; Snowling, Goulandris, Bowlby, \& Howell, 1986; Mann \& Liberman, 1984; Lundberg, Olofsson, \& Wall, 1980).

Phonology has attracted the research attention for many years and relatively less attention has been given to morphology. Many studies have been emerging in the lat few years focusing on the contribution of morphology to reading as an additional factor to phonology (Beauvillain \& Segni, 1992; Feldman, 1991; Caramazza, Laudanna, \& Romani, 1988; Feldman, 1994). Carlisle (1995) has suggested a definition to the term morphological awareness: "Morphological awareness focuses on children's conscious awareness of the morphemic structure of words and their ability to reflect on and manipulate the structure" (p. 194). There is clear evidence of a relationship between morphological awareness and reading in the early stages of reading (Carlisle, 1995; Champion, 1997; Fowler \& Liberman, 1995).

Although a serious database of research finding has been documenting the role of phonology and morphology in reading acquisition, not much has been known about the role of these variables in reading in different orthographies like Arabic. This study investigates the role of phonology (short vowelization) and complex Arabic morphology on the reading accuracy of highly skilled adult Arabic readers in reading morphological complex Arabic words and sentences. It is well known that skilled Arabic adult readers use textbooks with morphologically complex words, an indicator of their good level of literary Arabic. I will first present the nature of the Arabic orthography with its morphology and then a relevant review of the literature focusing on the rationale of the present study and its theoretical and practical contribution.

\section{Arabic Orthography}

Arabic is a language written in an alphabetic system of 28 letters, all consonants except three, the long vowels. Most Arabic letters have more than one written form, depending on the letter's place in a word: beginning, middle, or end. However, the essential shape of the letter is maintained in all cases (Abd El-Minem, 1987). In addition, the letters are divided into categories according to basic letter shapes, and the difference between them is the number of dots on, in or under the letter. Dots appear with 15 letters: 10 have one dot, three have two dots, and two have three dots. In addition to the dots, there are diacritical marks that contribute phonology to the Arabic alphabet (Abu-Rabia, 2001). Arabic words are a combination of consonants and vowels. Skilled and adult readers are expected to read texts without short vowelization, but this demands heavy reliance on context and other resources. Beginners and poor readers read texts with short vowelization. Vowelized Arabic is considered shallow orthography, and unvowelized Arabic is considered deep orthography. Reading accuracy in Arabic requires vowelizing word endings according to their grammatical function in the sentence, which is an advanced phonological and syntactical ability (Abu-Rabia, 2001). Silent reading comprehension is less strict, because the reader can rely on orthog- 
raphy, morphology, and other resources (Abu-Rabia, 2002).

Arabic morphology. Arabic morphology is built of two types of structures: derivational and inflectional.

Derivational morphology. All words in Arabic are based on phonological patterns built on roots that are consonantal patterns. Roots are triliteral or quadriliteral, that is, with three or four consonants. This is not a phonological unit but an abstract entity. The phonological pattern is constructed of: 1) short vowelization built onto roots. The phonological process does not break the orthographic order of the consonantal root; 2) patterns that include vowel letters, which are inserted between the root consonants. Here the phonological pattern of the infixes breaks the orthographic order of the consonantal root; 3 ) additional patterns with vowel letters that may come as prefixes or suffixes. The root conveys the initial lexical access and the combination of roots and phonological patterns conveys specific semantics (Frost, Forster, \& Deutsch, 1997).

The derivational morphology has two types of word patterns: verbal word patterns and nominal word patterns. There are 15 very frequent verbal word patterns in Arabic. Each verbal word pattern determines the inflectional pattern of the word (Abd El-Minem, 1987; Al-Dahdah, 1989; Wright, 1967). The verb pattern conveys basic semantics via verb roots, and it can change the meaning of a new word created from that root; different verb patterns built on the same root may convey different semantics (Abd El-Minem, 1987). There are nine nominal word patterns. There is semantic consistency in all these different nominal word patterns (Bentin \& Frost, 1995), some of which are more common than others. The derivations of nouns are constructed in two ways, one by addition of nominal patterns of the base roots and one by changing the past tense to the present tense by applying a phonological pattern to the latter (Abd El-Minem, 1987; Al-Dahdah, 1989; Wright, 1967).

Inflectional morphology. In contrast to the derivational process, in which the basic constituents are roots and word patterns, the inflectional morphological system in Arabic is constructed by attaching prefixes and suffixes to real words. The system of inflectional morphology of verbs is systematic and considers person, number, gender and time. In the past tense inflectional morphology shows person, number, and gender through the addition of suffixes to the basic verb pattern (third person masculine singular). In future and present tenses of verbs the inflectional morphology is also according to person, number, and gender, indicated by prefixes and sometimes suffixes. The imperative mood is formed for person, number, and gender by the addition of prefixes and suffixes (Abd El-Minem, 1987; Al-Dahdah, 1989; Wright, 1967). The inflectional morphological system of nouns considers gender, masculine/feminine; number, singular/plural, masculine and feminine; and pairs, masculine/feminine.

Most verbs and the majority of nouns are constructed out of roots of three consonants, occasionally two or four. Roots are built in phonological patterns to create specific words; these patterns may be a series of consonants or a series of vowels and consonants. As for roots and morphemic word patterns, most words in Arabic are constructed of two morphemes: the combination of a root and a word pattern creates the particular word. Different morphemes convey different types of information: the root conveys more information than the phonological pattern because it provides the core meaning of the word (Abu-Rabia, 2001, 2002), whereas the word patterns usually convey information on word class.
In sum, the combination of morphological units in Arabic is not linear, but relies on intertwining between two independent morphemes (the root and the word pattern). The order of root letters depends upon the word pattern and its way of intertwining with the root. The word pattern can be built of prefixes, suffixes and infixes, whose intertwining with the root can break the order of the root letters.

\section{Review of the Literature}

Morphology and reading. Research on the early stages of reading suggests that young children have basic and intuitive knowledge about the structure of words, morphology (Carlisle, 1995; Carlisle \& Nomanbhay, 1993; Champion, 1997; Clark \& Hecht, 1982; Tornéus, 1987). Clear evidence has been conveyed by some studies about the morphological awareness prediction of reading ability (Tornéus, 1987). Tornéus tested children's understanding of kindergarten children of novel compounds, for example, explain the meaning of grass bee and bee grass. She reported that morphological awareness of kindergarten pupil predicted their reading ability in the second grade. Similarly, Carlisle (1995) reported that morphological awareness of kindergarten children measured by morphological production tests predicted the reading comprehension in grade 2 . Some researchers argue that the exposure to print, seeing the same morpheme in different words, accelerates high morphological awareness to words when decoding them (Fowler \& Liberman, 1995).

Furthermore, Fowler and Liberman (1995) tested the relationship between phonology and morphology. They tested this relationship among grade 2 and 4 pupils. The students' vocabulary and reading and spelling abilities were measured in addition to their morphological production. The results indicated that only to ability to solve phonologically complex items separated poor from good readers. Fowler and Liberman (1995) suggested that differences in morphological awareness depend on differences in the phonological domain. In a study by Wunes, Bryant and Bindman (1997) investigated the development of morphological strategies of spelling in grade 2 and 4 pupils. They found that the students passed through successive stages of morphological spelling skills from grade 2 to grade 4 . The authors concluded that explicit morphological (grammatical) awareness of spoken language was accelerated by more experience with the specific orthography; reading and writing.

Furthermore, in a recent study by Arnbak and Elbro (2000) where they conducted a training study of morphological awareness involving 33 dyslexic students in grade 4 and 5. The training was oral and focused on semantic aspects of morphemes. During the training period, the experimental group gained significantly more than a similar group of untrained controls $(n=27)$ on one of three measures of morphological awareness. Both groups made equal progress on measures of phonological awareness, phoneme discrimination and picture naming. The experimental group progressed significantly more than the controls in reading comprehension and in spelling of morphologically complex words. The authors concluded that it is possible to develop dyslexic students' morphological awareness and that awareness of morphemes, the smallest meaningful units of language, may support the development of meaningoriented decoding strategies in reading and spelling.

Furthermore, Elbro and Arnbak (1996) investigated reading compounds (compared to other words) by Danish dyslexic 
adolescents and reading-age matched normal readers. They found that the dyslexic reader relied more sensitive to morphological structures compared to the normal readers. Namely, in Danish skilled readers may not depend on morphological segmentation and alternatively developed automatic visual recognition of words as whole entities.

Some researchers argue that the morphology of the language plays an essential role in reading and spelling, especially in the semitic languages: Arabic and Hebrew (Abu-Rabia, 2001; Abu-Rabia, Share \& Mansour, 2003; Beland \& Mimouni, 2001; Prunet, Béland, \& Idrissi, 2000; Ravid, 2001). Ravid (2001) argues that the morphology of Hebrew plays a major role in determining what letters are acquired first among children. She asserts that beginners rely on morphological cues of their familiar spoken language and look for those cues in the written language while learning spelling. Furthermore, Somech (2001) found that primary school children pronounced words according to morphological structures expected from the contexts of the story. Likewise, Beland and Mimouni (2001) assume that Arabic is a highly morphological language that heavily affects the reading strategy of the readers.

In a study by Prunet, Béland and Idrissi (2000) they argue that Arabic and all Semitic languages are addressed through the root morpheme, since the root is an autonomous semantic entity. They advocate that the lexicon of Semitic language readers is a root/morpheme-based lexicon. Such an approach supported from very early years by structuralists such as Cantineau (1950) and Harris (1951) where they recognized roots as autonomous morphemes expressing the basic meaning of the word, additional morphological information being expressed by a distinct vocalized pattern. This view was later discussed in an autosegmental analysis such as those of McCarthy (1981) and Hoberman (1988), which typically further separates vocalized patterns into morphemes consisting of vowels only or templates only. Such analysis implicitly or explicitly adopt a morpheme-based theory of morphology since their lexicon includes roots; expressing the basic meaning of the word. However, other Hebrew and Arabic grammarians also expressed different views (Saussure, 1978; Mahadin, 1982; Heath, 1987; Bat-El, 1994; Ratcliffe, 1997; Ussishkin, 1999). They viewed Semitic roots as paradigmatic relations existing between fully formed words, rather than as autonomous morphemes. Prunet, Béland and Idrissi (2000) in very thorough analysis of morphemebased theory in Semitic lexicons, they used data from bilingual aphasic patients. They argue that the consonant metathesis error (changing the order of root letters) provide evidence for the existence of roots as lexical units in the mental lexicon of speakers of Arabic. These errors differed quantitatively and qualitatively in Arabic and French. Their aphasic patients revealed parallel linguistic details in the two languages, and their metatheses must arise during the phonological planning stage in both languages. The same deficit yields different effects because the phonological representations of these languages are different (Béland \& Paradis, 1997; Paradis \& Prunet, 2000; Tranel, 1995). Of course, more recent psycholinguistic studies support the roots in Semitic languages (based on Hebrew) are semantic autonomous entities (Frost, Deutsch, Kenneth, \& Forster, 1997; Feldman, Frost, \& Pnini, 1995).

From the above brief literature review, it is clear that morphology is an important factor in reading acquisition. The present study investigates the role of roots in reading morphologi- cally complex words among native adult highly proficient Arabic readers.

Phonology and reading. The most important skill in phonological processing is the association of sounds with letters; that is, the understanding of grapheme-phoneme conversion rules and the exception of these rules. This ability is the basis of decoding print, and although there are other routes to obtain meaning from print, the phonological route is clearly an import ant one and critical in the early development of reading skills (Stanovich, 1988a, 1988b). Current theories of the development of reading skills in English stress phonological processing as the most significant underlying cognitive process. Arguments for this position are outlined in Stanovich (1988a, 1988b). Studies such as those of Bruck (1988), Ehri and Wilce (1983), Snowling (1980), Siegel and Ryan (1988) and Waters, Bruck and Seidenberg (1985) have shown that disabled readers have more difficulty reading unfamiliar words and pseudowords than normal readers matched on a chronological age or reading level. Further, this difficulty seems to be the fundamental problem of children with reading disability and often continues even to adulthood. Sometimes adults with a reading disability become like normal readers but still have difficulty reading pseudowords or read them very slowly (e.g., Barwick of Siegel, 1990; Bruck, 1990; Shafrir \& Siegel, 1991). Many studies have also shown that children's knowledge of the phonological structure of language is a good predictor of early reading ability (Bradley \& Bryant, 1983; Tunmer \& Nesdale, 1985; Mann, 1984; Olso, Wise, Conners, Rack, \& Fulker, 1989; Shankweiler \& Liberman, 1989), an impairment in the representation of processing of phonological information are implicated in at least some forms of developmental dyslexia (Manis, Seidenberg, Doi, McBride-Chang, \& Peterson, 1996; Stanovich, Siegel, \& Gottardo, 1997). Furthermore, skilled readers also rely on this information in identifying words (Van Orden, Pennington, \& Stone, 1990; Lukatela \& Turvey, 1994; Siedenberg, 1985; Jared \& Seidenberg, 1991; Perfetti \& Bell, 1991; Perfetti, Bell, \& Delaney, 1988).

The relationship between phonological awareness and reading ability has been tested in English and other languages, which resulted in compelling evidence that an understanding of the phonological constituents of words is an important determiner of reading success in many other alphabetic orthographies besides English (Durgunoğlu, Nagy, \& Hancia-Bhatt, 1993; Cardoso-Martins, 1995; Crossu, Shankweiler, Liberman, Katz \& Tola, 1988; Treiman, 1991; MacBride-Chang, 1995; Yopp, 1988).

\section{The Rationale of the Study}

The present study is aiming to investigate the role of the complex Arabic morphology in reading accuracy of adult native highly proficient readers. The Arabic complex morphology was rarely studied. The reading accuracy of the participants was tested via isolated morphological complex word recognition, sentences with morphological complex words preceded with priming roots and sentences without priming roots. Since morphology is always based on phonological patterns, the phonology (short vowelization mastery) is also tested in a way that each reading condition is presented, one with short vowelization and another equal condition without short vowelization.

The rationale of the present study is derived from the findings of a numer of studies in Arabic reading among regular, 
poor and dyslexic readers. Some of these reading studies indicated that the characteristics of Arabic slow it processing (Ivitar \& Ibrahim, 2003), such a finding questions the relevancy of reading fluency/speed as a testing measure. Others indicated that reading accuracy does not correlate with reading comprehension due to different resources involved (Abu-Rabia, 2001); and further studies indicated that phonology is a highly dominant factor in reading accuracy and reading comprehension across all ages and reading levels (Abu-Rabia, 1997, 1998, 2000, 2001, 2002; Abu-Rabia, Share, \& Mansour, 2003). Such a finding also questions the fluency of Arabic skilled readers. If phonology is highly influential on reading and reading comprehension, then the reading process is still slow to enable efficient phonological processing. These findings so far support this claim and fits the nature of the Arabic writing system. Reading scripts with and without short vowelization when testing reading accuracy demands pronouncing the short vowelization posted on letters with special focus on the final letter of the word because it indicates a grammatical function. Further studies indicated that the phonological stage in reading and spelling in Arabic orthography is a continuous stage that accompanies readers and spellers all their lives (Abu-Rabia \& Taha, 2004, 2006a, 2006b). The findings of Abu-Rabia and Taha (2006a) indicated that the percentage of phonological spelling errors were the highest among all grades from 1 to 9 .

As to the morphology, roots in Arabic are basic morphemes and considered autonomous semantic entities (Prunet, Béland, \& Idrissi, 2000) that enable lexical access to readers. If this is correct then priming roots in regular Arabic sentences should ease reading accuracy of target morphological high density words. As seen in the literature research focused usually on school children assuming that the role of morphology is crucial in the early stages of reading acquisition. This study investigates the role of morphology among highly skilled adult readers.

\section{Research Questions}

1) What is the role of the root or base word in reading morphologically complex words in context with vowels and without vowels?

2) What is the role of short vowelization in reading isolated morphologically complex words?

\section{Hypotheses}

1) Roots facilitate reading accuracy of morphologically complex words in context with vowels and without vowels.

2) The reading accuracy of the adult proficient readers will be significantly higher in the vowelized reading condition than the unvowelized reading condition in all reading conditions.

\section{Method}

Participants. Fifty-nine adult proficient native Arabic speakers were selected to participate in the study. They are university graduates in Arabic literature and working as Arabic language teachers in Arab schools. None of these adults has any sort of learning disorder according to their self-questionnaire report. Their chronological age range was 25 - 32 years. Each participant had at least 3 years of teaching experience. All the teachers volunteered to participate in this study.

\section{Materials and Research Design}

Six reading conditions were designed for the 59 adult participants. All the participants had to be tested on all these reading conditions for reading accuracy:

Condition 1. A list of 60 Arabic words, all are morphological high density words. The words were chosen from adult literary books. All the words were presented with full vowelization. The participants had to read all words aloud.

Condition 2. Another parallel list of 60 Arabic words, all are morphological high density words. The words are equivalent to the list in condition 1 as far as possible. However, this list is presented unvowelized. The participants had to read all the words aloud.

Condition 3. A list of 60 sentences with a base word and a target word. The target word is a highly morphological density word which is preceded by the a root. All the 60 sentences were presented with full vowelization. The distance between the root and the target word was two words. The participants were tested for the reading accuracy of the target word.

Condition 4. Another list of 60 sentences with a root and a target word. The target word is a highly morphological density word. All 60 sentences were presented unvowelized and the distance between the target word and the priming root was two words. The participants were tested for the reading accuracy of the target word.

Condition 5. A list of 60 sentences without a root but with a target word with high morphological density. These sentences have the same length and linguistic difficulty as the sentences in conditions 3 and 4 . All the sentences were presented with full vowelization. The participants were tested for the reading accuracy of the target word.

Condition 6. Another list of 60 sentences without a root word but with a target word with high morphological density. These sentences were parallel in linguistic difficulty and length to the sentences in condition 5. The participants were tested for reading accuracy.

Building the materials. All the testing materials were subjected to 10 Arabic experts, all high school or college Arabic teachers. They edited the tasks and had to rate them according to morphological gradual difficulty.

Scoring. Participants read all the reading conditions out loud. They were scored on the sentences reading conditions only on the target word should be read with thorough pronunciation of the whole short vowels.

\section{Procedure}

All the 59 participants had to read aloud in all 6 reading conditions because they were tested for reading accuracy. The reading of the participants was recorded. The testing took place in a quiet room in the teachers' schools. The lists of words and sentences were typed on transparencies and presented to the participants on an overhead. There was always a break of about 10 minutes between each reading condition. The order of tests was changed for each participant for counterbalancing purposes. The total average time for testing and breaks for each participant was about 2.5 hours. The total average time for testing only was 70 minutes.

\section{Results}

The data of this study was treated by a one-way ANOVA re- 
peated measure (within-subject factors), one group of one level readers. All the 59 participants were tested in the 6 reading conditions. Then the t-test analysis poor paired samples were applied to locate specific significant differences between the different reading conditions. Table 1 presents the means and standard deviations of the percentages of the correct answer in each reading condition.

As seen in Table 1 the best performance of these highly skilled adult Arabic readers is on reading vowelized sentences with roots that preceded the target word while the poorest condition of the same readers is our reading unvowelized sentences and without roots. The one way ANOVA repeated measures indicated a main effect for reading condition, multivariate test of within-subjects factors, Wilks' Lambda $\mathrm{F}(5,54)=368.988, p$ $<0.001$. For further analysis the t-test analysis for paired samples was used in this case to test the specific differences of reading conditions. When reading vowelized words was compared with unvowelized words the difference was significant for the benefit of the vowelized condition $\mathrm{t}(2,58)=19.765, p<$ 0.001 ; vowelized sentences with roots vs. unvowelized sentences with roots the differences were significant for the vowelized sentences $\mathrm{t}(1,58)=-9.48, p<0.001$; vowelized sentences without roots vs. unvowelized sentences without roots vs. unvowelized sentences without roots the differences were significant for the benefit of the vowelized sentences $t(1,58)=$ $4.80, p<0.001$; vowelized sentences with roots vs. vowelized sentences without roots, the difference was significant for the benefit of the base-words condition $\mathrm{t}(1,58)=-367.93, p<$ 0.001 ; and when unvowelized sentences with roots were compared with unvowelized sentences without bas words the difference was significant for the benefit of the base-words condition $\mathrm{t}(12,58)=-29.65, p<0.001$. Figure 1 illustrates usually the mean percentages of performance of the same reading group on the 6 reading conditions.

In sum, there were significant differences between the 6 reading conditions. The best reading condition was when sentences were vowelized with roots $(88.33 \%)$ and followed by the reading condition when sentences were presented without vowelization and with roots $(77.23 \%)$, the poorest results were when isolated words were presented unvowelized (20.28\%).

\section{Discussion}

The most important findings of this study are that, 1) roots facilitate reading accuracy of highly proficient adult readers in reading morphological complex words, with and without short vowelization; 2) short vowelization facilitate reading accuracy of morphological complex words of highly proficient native adult readers; 3 ) short vowelization facilitate reading accuracy of reading morphologically complex words in sentential context compared to the same reading condition without short vowelization.

The first finding indicates that roots facilitate reading accuracy of target words that are morphological complex. These adult proficient Arabic readers, their accuracy in this reading condition was one of the highest positive results although these sentences were presented without short vowelization (see Figure 1). Namely, roots facilitate reading accuracy, since these roots trigger orthographic lexical information that was retrieved directly to assist in identification of morphologically complex Arabic words. This is because roots are semantic autonomous entities. The results here are similar to previous results of Abu-Rabia and Awwad (2004), where they found in a computerized priming paradigm that the differences between the phonological pattern results and the roots' results are not significant. Namely, both phenology and morphology (roots) contribute, maybe equally, to reading Arabic. The results of Abu-Rabia and Awwad probably because the material used was with familiar words. The results of this specific reading condition in the present study testing reading accuracy indicate optimal superiority of orthographic word knowledge when reading morphological complex words in context. Generally, these results accord with previous results conducted in different orthographies which indicated the importance of the role of the morphology in reading Arabic (Abu-Rabia, 2001; Abu-Rabia,

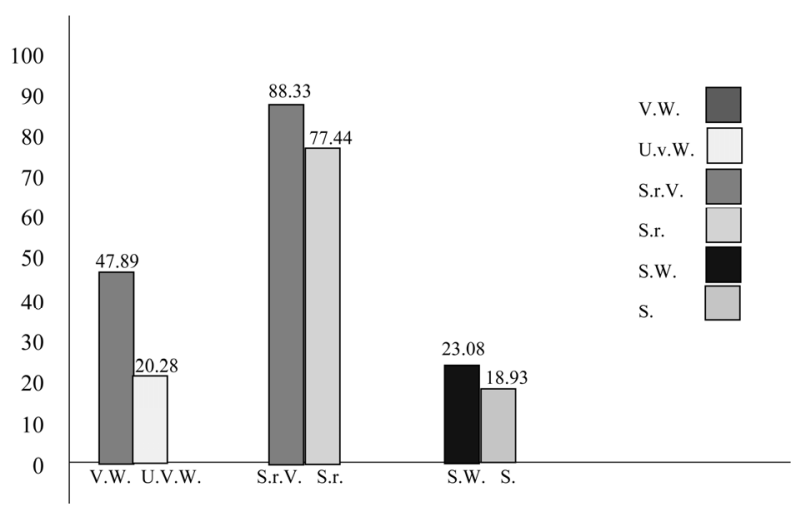

Figure 1.

Visual illustration of mean percentages of success on all 6 reading conditions $(\mathrm{n}=59)$. U.V. = vowelized words; U.v.W. = unvowelized words; S.r.V. $=$ sentence + root + vowelization; S.r. $=$ sentence + root; S.W. $=$ sentence without roots with vowelization; S. $=$ sentences without roots and without vowelization.

Table 1.

Means and standard deviations of percentages of correct answers in each reading condition (N-59).

\begin{tabular}{ccc}
\hline Reading condition & Mean & SD \\
\hline Unvowelized words & 20.28 & 10.61 \\
Vowelized words & 47.89 & 8.31 \\
Sentences with roots, target and vowelization & 88.33 & 7.77 \\
Sentences with roots and target words without vowelization & 77.44 & 8.35 \\
Sentences without roots-with target word with vowelization & 23.08 & 7.85 \\
Sentences without roots without vowelization & 18.93 & 8.25
\end{tabular}


Share, \& Mansour, 2003; Beland \& Mimouni, 2001; Abu-Rabia \& Taha, 2006a, 2006b), and in Hebrew (Ravid, 2001; Share \& Levin, 1999; Ben-Dror, Bentin, \& Frost, 1995) and more specific in Hebrew the role of root in reading Hebrew (Frost, Forster, \& Deutsch, 1997; Frost \& Bentin, 1995), and in Latin orthography (Clark \& Hecht, 1982; Tornéus, 1987; Carlisle, 1995; Fowler \& Liberman, 1995; Arnbak \& Elbro, 1996, 2002). Although the results of the present study are similar to the results of the studies mentioned above, still most of the above studies were conducted among young children going through their primary school believing that the role of morphology ends when readers become skilled and adults. However, the present study presents results of native adult highly skilled Arabic readers whose reading skills are well mastered and still are significantly affected by the separate morphemes of the morphological complex words while reading. Namely, reading among these readers occurs via morphological decomposing (Taft, 1991; Beauvillain \& Segeui, 1992; Pinker, 1997). This morphological decomposing is need due to the high morphological complexity of the Arabic words, which demands the readers to rely on roots for identification meaning and initial lexical access, which is called the root/morpheme based theory (Abu-Rabia, 2001; Taft, 1981; Taft \& Forster, 1975; Prunet, Béland, \& Idrissi, 2000), where the functional nature of derivational and inflectional processing is considered similar. Both are affiliated with the same level of analysis regardless of their lexicon representation, namely under the word morphology or under the semantics of the word. The supporters of this approach do encode the morphological structure and argue that the morphological information is helpful in the word identification process (Taft, 1991; Taft \& Forster, 1975; Prunet, Béland, \& Idrissi, 2000).

In Arabic, and because of the complexity of the Arabic morphology, the semantics of the root morpheme as a semantic entity is helpful and accessible for initial lexical access, initial understanding and later connected the rest of the affixes (morphemes) to construct the exact phonological representation (pattern) (Prunet, Béland, \& Idrissi, 2000; Frost et al., 1997; Feldman et al., 1995). Thus, since roots (morphemes) are crucial in identification of morphological complex Arabic words and phonology is retrieved later which slows its processing (Ivitar \& Ibrahim, 2003), this questions the relevancy of fluency, speed and automaticity in reading Arabic when testing reading accuracy (reading aloud) (Abu-Rabia, 2001; SaieghHaddad, in press).

Since roots of words revealed good assistance for highly skilled adult readers, this confirms the morpheme/root-based theory in Semitic languages. This theory receives more confirmation from more studies conducted on aphasic patients. These studies revealed that the Arabic metatheses (keeping the root letter but in some different order) are more frequent than other non-Semitic languages among the same aphasic patients. In the study of Prunet, Béland and Idrissi (2000), a patient produced five consonant metatheses in French as opposed to 119 in Arabic. It seems that this result is explained by arguing that the morphemic and floating nature of Arabic root consonants compared to the non-morphemic and pre-anchored nature of French consonants. Other studies based on error analysis confirmed this conclusion in different Semitic languages (Béland \& Paradis, 1997; Béland et al., 1999; Berman, 1981).

Idrissi et al. (2000) argue that these results are because the "... consonants of French are more stable than those of Arabic because they are pre-anchored. This entails that Arabic consonants are not pre-anchored, which means that they form roots" (p. 633). In both languages, the consonants are ordered, but the order of Arabic roots need only contain precedence relations on one order. This while in Indo-European languages consonants must contain precedence relations on both melodic and skeletal tiers in addition to information about how the units on both tiers are connected to one another (Idrissi et al., 2000). Further, whatever formalism is used to express precedence, the order of segments should be more stable in Indo-European than in Semitic because the links between the prosodic and segmental tiers are memorized rather than derived by rules, principles, or constraints (Idrissi et al., 2000).

As to the second finding that short vowelization of morphological complex words facilitates reading accuracy among highly proficient adult native Arabic readers, this result is not new. It accords strongly with previous results obtained by Abu-Rabia among high school and university students (AbuRabia, 1997a, 1997b, 1998, 2001). The university native Arabic students were tested on reading isolated words with and without vowels and on reading comprehension of texts with and without vowels. The results indicated that even among adults, the short vowelization had a significant effect on their reading accuracy and their reading comprehension. Such a result was confirmed in Hebrew reading comprehension among highly adult proficient Hebrew readers (Shimron \& Sivan, 1994). The significant effect of vowels on reading morphologically complex words among highly proficient adult readers means that the phonological stage in reading Arabic is a continuous stage that accompanies even highly skilled adult Arabic readers all their lives. Such a finding is divergent from results obtained from other orthographies; that phonology is an initial stage in reading and writing, and that for readers to become fluent, they should rely on their automatic lexical-visual-recognition of words, based on their rich orthographic mental lexicon (Lennox \& Siegel, 1993; Snowling, 1987; Snowling, Defty, \& Goulandris, 1996; Bruck, 1989; Stanovich, 1994; Ellis, 1993; Steffler, 2001; Frith, 1985; Temple, 1986, Perfetti, 1992; Seymor, 1990; Share, 1995; Stanovich \& Siegel, 1994). As to the third finding that short vowelization facilitated reading accuracy of morphological complex words when they were in sentential context, this finding accord with previous results, that even when the sentential context is presented, for reading accuracy the vowels are very crucial, especially for pronouncing short vowelization posted on ends of words to indicate grammatical faction. Such a task is required for reading accuracy (reading aloud) not necessary in silent reading comprehension, which leads to a lack of positive significant correlation between reading accuracy and reading comprehension in Arabic orthography (Abu-Rabia, 2001; Saiegh-Haddad, in press).

Furthermore, in this study, it is argued that if the reading accuracy of these Arabic highly proficient readers always needs phonology (short vowelization), namely, the phonological stage in Arabic reading development is continuous. This leads to the conclusion that there is no skilled reader in Arabic, this if we adopt the definition of the skilled reader, as it is in the reading literature today. Some studies in the orthography of Arabic indicate that the phonological stage in reading and spelling is a continuous stage that accompanies readers and writers all their lives (Abu-Rabia \& Taha, 2004, 2006a, 2006b). These findings suggest that the highest percentage rate of reading and spelling errors made by readers was mainly phonological. Such a find- 
ing enhances the phonological findings (short vowelization) of the present study. Such a finding challenges reading development of the reading theory today which leads scholars to consider more cross orthographic studies for more expanded, comprehensive and revised reading theory.

In sum, reading morphological complex words in Arabic even by native adult highly skilled Arabic readers occurs via a morphological decomposing process which slows word recognition process (Iviatar \& Ibrahim, 2003). One of the key words for reading accuracy of morphological complex words in Arabic orthography is the root for initial lexical access. Furthermore, short vowelization is needed to facilitate reading accuracy in isolation and in sentential context. Namely, morphological knowledge and short vowelization are the key variables in the process of reading accuracy even among adult highly skilled readers.

I would like to end this discussion with the words of a great Arabic grammarian who depicted the morphological complexity of the Arabic language. Those are the words of Al-Khalil ibn Ahmad who was born in 718 CE, Oman and died in 791, Persia (cited in Al-Makhzuumii \& As-Saamarraaii, 1988):

Know that the biradical root may be permut[ed] in two ways, like qad-daq, šad-daš. The triradical root may be permut[ed] in six ways: this is called "six-way variation", like $d$ bara-barad a-bad ara-rad aba-rabad $a$. The quadriradical root may be permut[ed] in twenty-four ways, because each of its four radicals may be combined with the six permutations of the triradical roots, making a total of twenty-four ways.

\section{REFERENCES}

Abd El-Minem, F. M. (1987). Elm al-sarf. Jerusalem: Al-Taufik Press. (in Arabic)

Abu-Rabia, S. (1997a). Reading in Arabic orthography: The effect of vowels and context on reading accuracy of poor and skilled native Arabic readers. Reading and Writing: An Interdisciplinary Journal, 9 , 65-78. doi:10.1023/A:1007962408827

Abu-Rabia, S. (1997b). Reading in Arabic orthography: The effect of vowels and context on reading accuracy of poor and skilled native Arabic readers in reading paragraphs, sentences and isolated words. Journal of Psycholinguistic Research, 26, 465-482. doi:10.1023/A:1025034220924

Abu-Rabia, S. (2001). The role of vowels in reading Semitic scripts: Data from Arabic and Hebrew. Reading and Writing: An Interdisciplinary Journal, 14, 39-59. doi:10.1023/A:1008147606320

Abu-Rabia, S. (2002). Reading in a root-based morphology language. Journal of Research in Reading, 25, 299-309. doi:10.1111/1467-9817.00177

Abu-Rabia, S., \& Abu-Rahmoun Zahir, N. (in preparation). The role of morphology and phonology in reading accuracy and comprehension of dyslexic and normal native Arabic speakers.

Abu-Rabia, S., \& Awwad, Y. (2004). Morphological structures in visual word recognition: The case of Arabic. Journal of Research in Reading, 27, 321-336. doi:10.1111/j.1467-9817.2004.00235.x

Abu-Rabia, S., \& Taha, H. (2004). Reading and spelling error analysis of native Arabic dyslexic readers. Reading and Writing: An Interdisciplinary Journal, 17, 651-689. doi:10.1007/s11145-004-2657-x

Abu-Rabia, S., \& Taha, H. (2006). Reading in Arabic orthography. In R. M. Joshi, \& P. G. Aaron (Eds.), Handbook of orthography and literacy (pp. 321-338). Abingdon: Lawrence Erlbaum Associates.

Abu-Rabia, S., Share, D., \& Mansour, M. (2002). Word recognition and basic cognitive processes among reading-disabled and normal readers in Arabic. Reading and Writing: An Interdisciplinary Journal, 16, 423-442. doi:10.1023/A:1024237415143
Al-Dahdah, A. (1989). The grammar of the Arabic language in tables and lists. Beirut: Maktabat Lebanon. (in Arabic)

Arnbak, E., \& Elbro, C. (2002). The effects of moshpological awareness training on the reading and spelling skills of young dyslexics. Scandinavian Journal of Educational Research, 44, 229-251. doi:10.1080/00313830050154485

Barwick, M., \& Siegel, L. S. (1990). The incidence and nature of learning disabilities in runaway homeless youth. Unpublished manuscript.

Bat-El, O. (1994). Stem modification and cluster transfer in Modern Hebrew. Natural Language \& Linguistic Theory, 12, 571-596. doi:10.1007/BF00992928

Beauvillain, C., \& Segui, J. (1992). Representation and processing of morphological information. In R. Frost, \& L. Katz (Eds.), Orthography, phonology and meaning. Amsterdam: Elsevier Science Pubs.

Beland, R., \& Mimouni, Z. (2001). Arabic-French bilingual aphasic patients. Cognition, 82, 77-126.

Ben-Dror, I., Bentin, S., \& Frost, R. (1995). Semantic, phonological and morphological skills in reading disabled and normal children. Reading Research Quarterly, 30, 876-893. doi:10.2307/748202

Bentin, S., \& Frost, R. (1995). Morphological factors in visual word recognition in Hebrew. In L. Feldman (Ed.), Morphological aspects of language processing (pp. 217-292). Hillsdale, NJ: Erlbaum.

Bradley, L., \& Bryant, P. (1983). Categorizing sounds and learning to read: A causal connection. Nature, 301, 419-421. doi: $10.1038 / 301419 \mathrm{a} 0$

Bruck, M. (1988). The word recognition and spelling of dyslexic children. Reading Research Quarterly, 83, 51-68. doi:10.2307/747904

Bruck, M. (1990). Word-recognition skills of adults with childhood diagnosis of dyslexia. Developmental Psychology, 26, 439-454. doi:10.1037/0012-1649.26.3.439

Cantineau, J. (1950). La notion de "scheme" et son alteration dans diverses langues sémitiques. Semitica, 3, 73-83.

Caramazza, A., Laudanna, A., \& Romani, C. (1988). Lexical access in inflectional morphology. Cognition, 28, 207-332. doi:10.1016/0010-0277(88)90017-0

Carlisle, J. F. (1995). Morphological awareness and early reading achievement. In L. B. Feldman (Ed.), Morphological aspects of language processing. Hillsdale, NJ: Lawrence Erlbaum.

Champion, A. (1997). Knowledge of suffixed words: A comparison of reading disabled and nondisabled readers. Annals of Dyslexia, 47, 29-55. doi:10.1007/s11881-997-0019-5

Clark, E. V., \& Hecht, B. F. (1982). Learning to coin agent and instrument nouns. Cognition, 12, 1-24. doi:10.1016/0010-0277(82)90027-0

Durgunoğlu, A. Y., Nagy, W. E., \& Hancin-Bhatt, B. J. (1993). Crosslanguage transfer of phonological awareness. Journal of Educational Psychology, 85, 453-465. doi:10.1037/0022-0663.85.3.453

Ehri, L. C., \& Wilce, L. S. (1983). Development of word identification speed in skilled and less skilled beginning readers. Journal of Educational Psychology, 75, 3-18. doi:10.1037/0022-0663.75.1.3

Ellis, N. C. (1994). Longitudinal studies of spelling development. In: G. D. A. Brown, \& N. C. Ellis (Eds.), Handbook of spelling: Theory, process and intervention (pp. 155-177). Chichester: John Wiley \& Sons.

Erlbo, C., \& Arnbak, E. (1996). The role of morpheme recognition and morphological awareness in dyslexia. Annals of Dyslexia, 46, 209240. doi:10.1007/BF02648177

Feldman, L. B. (1991). The contribution of morphology to word repetition. Psychological Research, 53, 33-41. doi:10.1007/BF00867330

Feldman, L. B. (1994). Beyond orthography and phonology: Differences between inflections and derivations. Journal of Memory \& Language, 33, 442-470. doi:10.1006/jmla.1994.1021

Fowler, A. E., \& Liberman, I. Y. (1995). The role of phonology and orthography in morphological awareness. In L. B. Feldman (Ed.), Morphological aspects of language processing. Hillsdale, NJ: Lawrence Erlbaum.

Frith, U. (1985). Beneath the surface of developmental dyslexia. In K. E. Peterson, J. C. Marshall, \& M. Coltheart (Eds.), Surface dyslexia (pp. 301-330). Hillsdale, NJ: Erlbaum.

Frost, R., \& Bentin, S. (1992). Reading consonants and guessing vowels: Visual word recognition in Hebrew orthography. In R. Frost, \& 
L. Katz (Eds.), Orthography, phonology, morphology and meaning (pp. 27-44). Amsterdam: Elsevier.

doi:10.1016/S0166-4115(08)62787-9

Frost, R., Forster, K., \& Deutsch, A. (1997). What we can learn from the morphology of Hebrew? A masked-priming investigation of morphological representation. Journal of Experimental Psychology, Learning, Memory, and Cognition, 23, 829-856. doi:10.1037/0278-7393.23.4.829

Harris, Z. S. (1951). Structural linguistics. Chicago, IL: University of Chicago Press.

Heath, J. (1987). Albaut and ambiguity: Phonology of a Moroccan Arabic dialect. Albany: State University of New York Press.

Iviatar, Z., \& Ibrahim, R. (2003). The characteristics of Arabic slow its processing. Neuropsychology, 16, 322-326.

Jared, D., \& Seidenberg, M. S. (1991). Does word identification proceed form spelling to sound to meaning? Journal of Experimental Psychology: General, 120, 358-394. doi:10.1037/0096-3445.120.4.358

Lennox, C., \& Siegel, L. S. (1993). Visual and phonological spelling errors in subtypes of children with learning disabilities. Applied Psycholinguistics, 14, 473-488. doi:10.1017/S0142716400010705

Liberman, I. Y., \& Liberman, A. M. (1990). Whole word vs. code emphasis: Underlying assumptions and their implication for reading instruction. Bulletin of the Orthon Society, 40, 51-76.

Lukatela, G., \& Turvey, M. T. (1994). Visual lexical access is initially phonological: I. Evidence from associative priming by words, homophones, and pseudohomophones. Journal of Experimental Psychology: General, 123, 107-128. doi:10.1037/0096-3445.123.2.107

Lundberg, I., Olofsson, A., \& Wall, S. (1980). Reading and spelling skills in the first school years predicted from phonemic awareness skills in kindergarten. Scandinavian Journal of Psychology, 21, 159173. doi:10.1111/j.1467-9450.1980.tb00356.x

MacBride-Chang, C. (1995). What is phonological awareness? Journal of Educational Psychology, 8, 179-192. doi:10.1037/0022-0663.87.2.179

Mahadin, R. S. (1982). The morphophonemics of the standard Arabic triconsonantal verbs. Doctoral dissertation, Philadelphia: University of Pennsylvania.

Manis, F., Seidenberg, M., Doi, L., McBride-Chang, C., \& Peterson, A. (1996). On the basis of two subtypes of developmental dyslexia. Cognition, 58, 157-195. doi:10.1016/0010-0277(95)00679-6

Mann, V. A. (1984). Longitudinal prediction and prevention of early reading difficulty. Annals of dyslexia, 34, 115-136. doi:10.1007/BF02663616

Mann, V. A., \& Liberman, I. Y. (1984). Phonological awareness and verbal short-term memory: Can they presage early reading problems? Journal of Learning Disabilities, 17, 592-599. doi: $10.1177 / 002221948401701005$

McCarthy, J. J. (1981). A prosodic templates, morphemic templates, and morphemic tiers. In H. V. Hulst, \& N. Smith (Eds.), The structure of phonological representations (2nd ed., pp. 191-223), Foris: Dordrecht.

Olson, R., Wise, B., Conners, F., Rack, J., \& Fulker, D. (1989). Specific deficits in component reading and language skills: Genetic and environmental influences. Journal of Learning Disabilities, 22, 339348. doi:10.1177/002221948902200604

Perfetti, C. A., \& Bell, L. (1991). Phonemic activation during the first $40 \mathrm{~ms}$ of word identification: Evidence from backward masking and priming. Journal of Memory and Language, 30, 473-485. doi:10.1016/0749-596X(91)90017-E

Perfetti, C. A., Bell, L., \& Delaney, S. (1988). Automatic phonetic activation in silent word reading: Evidence from backward masking. Journal of Memory and Language, 27, 59-70.

doi:10.1016/0749-596X(88)90048-4

Pinker, S. (1987). Words and rules in human brain. Nature, 387, 547548. doi: $10.1038 / 42347$

Purnet, J. F., Béland, R. \& Idrissi, A. (2000). The mental representation of semitic words. Linguistic Inquiry, 31, 609-648. doi: $10.1162 / 002438900554497$

Rabia, S., \& Taha, H. (2006a). Reading in Arabic orthography. In R. M. Joshi, \& P. G. Aaron (Eds.), Handbook of orthography and literacy.
Abingdon: Lawrence Erlbaum Associates.

Ravid, D. (2001). Learning to spell in Hebrew: Phonological and morphological factors. Reading and writing: An Interdisciplinary Journal, 14, 459-485.

Ratcliffe, R. R. (1997). Prosodic templates in a word-based morphological analyhsis of Arabic. In M. Eid, \& R. R. Ratcliffe (Eds.), Perspectives on Arabic Linguistics $X$ (pp. 147-171). Amsterdam: John Benjamins.

Saiegh-Haddad, E. (in Press). The effect of diglossic variables on reading. Applied Psycholinguistics.

Saussure, F. D. (1978). Cours de Linguistique générale. Paris: Payot.

Shafrir, U., \& Siegel, L. S. (1991). Cognitive processes of subtypes of adults with learning disabilities. Unpublished manuscript.

Shankweiler, D., \& Liberman, K. (1989). Phonology and reading disability: Solving the reading puzzle. Ann Arbor, MI: University of Michigan Press.

Share, D. (1995). Phonological recoding and self-teaching: Sine qua non of reading acquisition. Cognition, 55, 151-218. doi: 10.1016/0010-0277(94)00645-2

Share, D., \& Levin, I. (1999). Learning to read and write in Hebrew. In M. Hjarris, \& G. Hatano (Eds.), Learning to read and write: A crosslinguistic perspective (pp. 89-111). Cambridge: Cambridge University Press.

Shimron, J., \& Sivan, T. (1994). Reading proficiency and orthography: Evidence from Hebrew and English. Language Learning, 44, 5-27. doi:10.1111/j.1467-1770.1994.tb01447.x

Siedenberg, M. S. (1985). The time course of information activation and utilization in visual word recognition. In D. Besner, T. G. Waller, \& E. M. MacKinnon (Eds.), Reading research: Advances in theory and practice (pp. 199-252). New York: Academic Press.

Siegel, L. S., \& Ryan, E. B. (1988). Development of grammatical sensitivity, phonological, and short-term memory in normally achieving and learning disabled children. Developmental Psychology, 24, 28-37. doi:10.1037/0012-1649.24.1.28

Snowling, M. (1980). The development of grapheme-phoneme correspondence in normal and dyslexic readers. Journal of Experimental Child Psychology, 29, 294-305. doi:10.1016/0022-0965(80)90021-1

Stanovich, K. E. (1988a). Explaining the differences between the dyslexic and garden variety poor reader. The phonological-core variance-differences model. Journal of Learning Disabilities, 21, 590604. doi: $10.1177 / 002221948802101003$

Stanovich, K. E. (1988b). The right and wrong places to look for the cognitive locus of reading disability. Annals of Dyslexia, 38, 154-177. doi: $10.1007 / \mathrm{BF} 02648254$

Stanovich, K. E. (1991). Discrepancy definitions of reading disability: Has intelligence led us astray? Reading Research Quarterly, 26, 7-29. doi: $10.2307 / 747729$

Stanovich, K. E., Cunningham, A. E., \& Cramer, B. B. (1984). Assessing phonological awareness in kindergarten children: Issues of task comparability. Journal of Experimental Child psychology, 38, 175190. doi:10.1016/0022-0965(84)90120-6

Stanovich, K. E., \& Siegel, L. S. (1994). Phenotypic performance profile of children with reading disabilities: A regression-based test of the phonological-core variable-difference model. Journal of Educational Psychology, 86, 24-53. doi:10.1037/0022-0663.86.1.24

Stanovich, K. E., Siegel, L. S., \& Gottardo, A. (1997). Converging evidence for phonological and surface subtypes of reading disability. Journal of Educational Psychology, 89, 114-127. doi:10.1037/0022-0663.89.1.114

Taft, M. (1981). Prefixed stripping revisited. Journal of Verbal Learning and Verbal Behavior, 20, 289-297. doi:10.1016/S0022-5371(81)90439-4

Taft, M. (1991). Reading and the mental lexicon: Essays in cognitive psychology (pp. 93-106). Hillsdale, NJ: Erlbaum.

Taft, M., \& Forster, K. I. (1975). Lexical storage and retrieval of prefixed words. Journal of Verbal Learning and Verbal Behavior, 14, 638-647. doi:10.1016/S0022-5371(75)80051-X

Temple, C. M. (1988). Red is read but eye is blue: A case study of developmental dyslexia and follow-up report. Brain and Language, 34, 130-137. doi:10.1016/0093-934X(88)90122-8

Tornéus, M. (1987). The importance of metaphonological and meta- 


\section{S. ABU-RABIA}

morphological abilities for different phases of reading development. Paper presented at the Third World Congress of Dyslexia, Crete.

Treiman, R. (1992). The role of intrasyllabic units in learning to read and spell. In P. Gough, L. Ehri, \& R. Treiman (Eds.), Reading acquisition. Hillsdale, NJ: Erlbaum.

Tunmer, W. E., \& Nesdale, A. R. (1985). Phonetic segmentation skill and beginning reading. Journal of Educational Psychology, 77, 417427. doi:10.1037/0022-0663.77.4.417

Ussishkin, A. P. (1999). The inadequacy of the consonantal root: Modern Hebrew denominal verbs and output-output correspondence. Phonology, 16, 401-442. doi:10.1017/S0952675799003796
Van Orden, G. C., Pennington, B. F., \& Stone, G. O. (1990). Word identification in reading and the promise of subsymbolic psycholinguistics. Psychological Review, 97, 488-522. doi:10.1037/0033-295X.97.4.488

Waters, G. S., Bruck, M., \& Seidenberg, M. (1985). Do children use similar processes to read and spell words? Journal of Experimental Child Psychology, 39, 511-530. doi:10.1016/0022-0965(85)90054-2

Wright, W. (1967). A grammar of the Arabic language. Cambridge: Cambridge University Press.

Yopp, H. K. (1988). The validity and reliability of phonemic awareness tests. Reading Research Quarterly, 23, 159-177. doi:10.2307/747800 